\title{
Treinta años de Administración Autonómica en las Islas Baleares(Reflexiones sobre los cambios producidos por los Estatutos de Autonomía de 1983 y 2007) ${ }^{1}$
}

\author{
Joana M. Socias Camacho \\ Profesora Titular de Derecho Administrativo \\ Universidad de las Islas Baleares \\ joana.socias@uib.es \\ Recibido: 10 de mayo de 2012 \\ Aceptado: 18 de julio de 2012
}

\begin{abstract}
Resumen
La Comunidad Autónoma de las Islas Baleares dispone hoy de una Administración de notable relieve, resultado del proceso de desarrollo del modelo de Estado de las autonomías. En este artículo se pretende ofrecer una visión panorámica de cómo ha ido evolucionando la Administración autonómica durante los últimos treinta años hasta hoy en día, reflexionando sobre los principales cambios producidos por los Estatutos de Autonomía de 1983 y 2007. Así, a partir de las previsiones estatutarias en materia de organización de las instituciones de autogobierno, de estructuración de una Administración propia y de régimen jurídico de la Administración, este trabajo aborda el marco jurídico que ha sustentado -y sustenta- el despliegue de la Administración autonómica. Pero también analiza el entramado organizativo autonómico, incluyendo la organización ordinaria pero también la instrumental, así como las últimas medidas adoptadas en materia de simplificación y transparencia administrativa, en clara sintonía con la normativa comunitaria y la integración europea.
\end{abstract}

Palabras clave

Derecho público autonómico; administración pública; organización administrativa; estatuto de autonomía de las islas baleares; comunidad autónoma de las islas baleares.

\section{Thirty years of Autonomic Administration in the Balearic Islands (Reflections on the changes produced by the Statutes of Autonomy of 1883 and 2007)}

\begin{abstract}
The Autonomous Community of the Balearic Islands now has a significant management, result in the development process model of the autonomous state. This article aims to provide an overview of trends over the autonomous administration for the past thirty years until today, reflecting on the major changes brought about by the Statute of Autonomy of 1983 and 2007. Thus, from the statutory provisions on the organization of self-government institutions, of building a self-management and legal status of the Administration, this paper addresses the legal framework that has supported-and-supports the deployment of the Administration autonomous. But it also analyzes the regional organizational framework, including the ordinary organization but also instrumental and the recent measures on simplification and administrative transparency, in tune with Community law and European integration.
\end{abstract}

Key words

Autonomous public law; public administration; administrative organization; statute of autonomy of the Balearic Islands; autonomous community of the Balearic Islands.

1 Líneas de investigación: Derecho del turismo y de la ordenación del territorio; Derecho del medio ambiente y del litoral; Derecho de la organización administrativa (administración instrumental y, específicamente, fundaciones del sector público; Servicios públicos impropios (en especial, taxis). 


\section{EL DESPLIEGUE DE LA ADMINISTRACIÓN DE LA COMUNIDAD AUTÓNOMA DE LAS ISLAS BALEARES: MARCO JURÍDICO}

La Constitución de 1978 supone un cambio trascendental en el sistema jurídico español. Incorpora el sistema de valores que ha de informar de todo el ordenamiento, refleja una concepción política en la que adquieren singular relieve los derechos fundamentales y libertades públicas, y diseña un nuevo modelo de Estado compuesto, el Estado de las Autonomías, basado en la distribución del Poder del Estado (Gómez-Ferrer, 1999)². Se sientan las "bases constitucionales" del Derecho público español -en la clásica expresión de Vedel-, que se van a referir, de un lado, a la constitución de un "Estado social y democrático de derecho" -según reza el artículo 1.1-, y de otro, a los principios de "unidad de la Nación española", de "autonomía de las nacionalidades y regiones que la integran" así como de "solidaridad entre todas ellas" -como dispone el artículo 2-, principios todos ellos estructuradores del régimen político español y que inciden plenamente en la delimitación de la Administración pública y del Derecho administrativo.

El sistema constitucional, que sitúa en la parte central del Texto Fundamental a los ciudadanos y a sus derechos de signo liberal, democrático y social, también determina y diseña el instrumento necesario para la efectividad de tales derechos, y éste no es otro que la organización del poder público en su división horizontal -legislativo, ejecutivo y judicial- y vertical del poder -poder ejecutivo, personificado en la Administración del Estado y en las demás administraciones- (Ibidem), en el marco del modelo de Estado compuesto y descentralizado. Tras la aprobación de la Constitución de 1978 empieza a desarrollarse efectivamente el Estado de las autonomías, y todas las comunidades autónomas van adquiriendo poco a poco un protagonismo progresivo mediante la configuración de su Administración autonómica, de acuerdo con sus respectivos Estatutos de Autonomía.

La Comunidad Autónoma de las Islas Baleares dispone hoy de una Administración propia de notable relieve. Ello es así pese a que el Estatuto de Autonomía de 1983 (aprobado por la Ley Orgánica 2/1983, de 25 de febrero -en adelante, EAIB 19833-), así como también su reforma de 2007 (aprobada por la Ley Orgánica 1/2007, de 28 de febrero -en adelante, EAIB 2007-), hayan dedicado tan sólo dos escuetos artículos a la regulación de la Administración de la Comunidad (EAIB 1983, arts. 41 y 42², y EAIB 2007, arts. 79 y 80); artículos que, además, se sitúan numéricamente lejos de las disposiciones más sustanciosas relativas a la institución que dirige a la Administración, el Gobierno (EAIB 1983, arts. 33, 34, 35 y 36, y EAIB 2007, arts. 57, 58, 59 y 60). En la actualidad, el artículo 79 del EAIB 2007 establece que corresponde a la Comunidad Autónoma de las Islas Baleares “la creación y la organización de una Administración propia, en el marco de los principios generales y de las normas básicas de la legislación del Estado y del presente Estatuto", Administración que, como matiza luego el apartado 1 del artículo 80, tiene que contar, para el ejercicio de sus funciones, no sólo con una estructura central sino además con el apoyo externo de otras entidades públicas: los entes instrumentales, por un lado, y las islas y los municipios, por otro (Segura, 2008b)5.

El Estatuto de Autonomía de las Islas Baleares, ni en la primera ni en la vigente versión, no integra a la Administración de la Comunidad Autónoma dentro de lo que se conoce como el sistema institucional autonómico (art. 18 EAIB 1983, y art. 39 EAIB 2007), del que sí forman parte indiscutible por previsión explícita el Parlamento, el Gobierno, el Presidente de la Comunidad Autónoma y los Consejos Insulares de institucional autonómica esté formada por los órganos estatutarios mencionados (Calafell, 2008) ${ }^{6}$, no quiere decir que, junto con estos órganos básicos de poder -legislativo y ejecutivo-, la Administración no constituya un elemento esencial de la organización institucional de la Comunidad Autónoma. Así lo demuestra el hecho que el Capítulo VII, integrado por artículos 79 y 80 del Estatuto de autonomía -dedicados a la Administración de la Comunidad Autónoma- forma parte del extenso Título IV relativo a las instituciones de la Comunidad Autónoma, en el que también tienen cabida, además, otras organizaciones públicas, como por ejemplo las entidades locales (Capítulo V) y los órganos de consulta y asesoramiento (Capítulo VI)7, así como dos capítulos dedicados a las instituciones de control de los poderes (Capítulo VIII) ${ }^{8}$ y al régimen jurídico de la Comunidad Autónoma (Capítulo IX).

2 Gómez-Ferrer Morant, R. (1999): “Incidencia de la Constitución sobre el Derecho administrativo”, Revista de Administración Pública, 150, págs. $159-208$.

3 La Ley Orgánica 2/1983, de 25 de febrero, fue modificada por la Ley Orgánica 9/1994, de 24 de marzo, y por la Ley Orgánica 3/1999, de 8 de enero. Sobre el proceso autonómico y los trabajos previos que dieron lugar al texto estatutario de 1983 y a las reformas de 1994 y de 1999, véase Colom Pastor, B. (2004): Les claus polítiques del procés autonòmic balear, Institut d’Estudis Autonòmics, Govern de les Illes Balears, Palma.

4 Tras la modificación estatutaria mediante Ley Orgánica 3/1999, de 8 de enero, véanse los artículos 43 y 44 del Estatuto de Autonomía. 5 Segura Ginard, LL. (2008b): “Artículo 80. Ejecución de las funciones administrativas”, A. Blasco Esteve (dir.), Comentarios al Estatuto de Autonomía de las Islas Baleares, Thomson-Civitas, págs. 1016-1024.

6 Calafell Ferrà, V. (2008): “Artículo 39. Las instituciones”, A. Blasco Esteve (dir.), Comentarios al Estatuto de Autonomía de las Islas Baleares, Thomson-Civitas, págs. 645-653.

7 Consejo Consultivo de las Islas Baleares, Consejo Audiovisual de las Islas Baleares y Consejo Económico y Social.

8 Sindicatura de Cuentas. 
El despliegue de la Administración de la Comunidad balear empieza a iniciarse formalmente a raíz de la Constitución española de 1978 y del nacimiento del Estado de las autonomías, como ya se ha dicho, si bien durante la etapa preautonómica se constituyó el ente preautonómico de las Baleares como región administrativa de carácter provisional. Con la entrada en vigor de la Ley de Elecciones Locales de 1978 y del Real Decreto Ley del mismo año por el que se aprobó el régimen preautonómico del archipiélago Balear, la Diputación provincial de las islas se extinguió y se constituyeron el Consejo General Interinsular y los tres Consejos Insulares de Mallorca, Menorca y de Ibiza y Formentera. Ello permitió, por un lado, que se distribuyeran las competencias de la Diputación entre los órganos representativos del ente preautonómico y, por otra, que el Consejo General Interinsular recibiera las primeras competencias administrativas del Estado y pudiera delegar una parte de ellas a los tres Consejos Insulares (Colom, 2001: 99) ${ }^{9}$. Los miembros del Consejo General Interinsular y los diputados y senadores de las Islas Baleares elegidos en las primeras elecciones de 15 de junio de 1977 tuvieron una intervención muy importante en cuanto a la vía para acceder al autogobierno y a las competencias (Ibidem: 101), hasta que en 1983 se aprobó el primer Estatuto de Autonomía de las Islas Baleares.

En el primer periodo de vigencia del régimen preautonómico en las Islas Baleares (1979-1980), la Administración del Estado traspasó al Consejo General Interinsular materias tan diversas como actividades molestas, insalubres, nocivas y peligrosas, urbanismo, agricultura, ferias, transportes, administración local, sanidad y cultura. A partir de la aprobación del Real decreto de 1980, que reguló a todos los efectos el traspaso de servicios de la Administración del Estado a los entes preautonómicos, comenzó una segunda etapa de traspasos (1981-1982), caracterizada por la homogeneización del proceso y por la negociación multilateral a través de comisiones mixtas sectoriales, que hizo posible que durante esta etapa el Consejo General Interinsular asumiera competencias en transportes terrestres, agricultura, pesca y ganadería, servicios y asistencia social, sanidad, tiempo libre, intervención de precios, disciplina de mercado, industria y energía, administración local, cultura y estructuras comerciales y comercio exterior (Mora, 2008) ${ }^{10}$.

Pero no es hasta la aparición del texto estatutario el 1 de marzo de 1983, y de la asunción por parte de la Comunidad Autónoma de la competencia exclusiva en materia de "organización, régimen y funcionamiento de sus instituciones de autogobierno" (art. 10.1), que la Comunidad empieza a dictar de manera decidida normas específicas para "la creación y la estructuración de una administración pública propia”, dando así cumplimiento a la previsión incluida en el artículo 41 del Estatuto. A partir de la entrada en vigor del Estatuto, la autonomía provisional asumida por el Consejo General Interinsular entre 1979 y 1982 le corresponde a la Comunidad Autónoma con carácter definitivo (disposición transitoria octava, apartado segundo); y el Gobierno, como poder ejecutivo, asume la titularidad de los bienes y de los servicios del Consejo General Interinsular, como especifica el apartado tercero de la disposición mencionada. Por otro lado, el artículo 11.1 del Estatuto de 1983 establece que, en el marco de la legislación básica del Estado, corresponde a la Comunidad el desarrollo legislativo y la ejecución del "régimen jurídico y de responsabilidad de la Administración de la Comunidad Autónoma..., de acuerdo con las disposiciones contenidas al apartado 1.18 del artículo 149 de la Constitución". Y el artículo 33.3 del Estatuto dispone que "una ley del Parlamento aprobada por mayoría absoluta establecerá la organización del Gobierno, las atribuciones y el estatuto personal de cada uno de sus componentes".

De los artículos 10.1 y 11.1 del Estatuto de 1983 (y en el mismo sentido, los artículos 30.1 y 31.1 del Estatuto de 2007) se deduce que la competencia que tiene la Comunidad Autónoma para establecer la organización administrativa propia está limitada por la competencia que tiene el Estado para regular "las bases del régimen jurídico de las administraciones públicas", en el sentido previsto en el artículo 149.1.18 de la Constitución. La jurisprudencia constitucional ha considerado que la definición de las bases por parte del Estado tiene por objeto crear un marco normativo unitario dentro del cual la Comunidad disponga de un margen de actuación que le permita, mediante la técnica del desarrollo legislativo, establecer las normas que satisfagan sus intereses peculiares (Cabotà, 2008$)^{11}$. Según la doctrina del Tribunal Constitucional, el Estado, en virtud de la competencia para regular las bases del régimen jurídico, tiene que regular todo el ordenamiento institucional de las administraciones públicas (STC 99/1987, de 11 de junio), así como también las relaciones entre las administraciones como la coordinación y las transferencias o delegaciones de funciones administrativas (STC 76/1983, de 5 de agosto). Pero en cuanto a los aspectos estructurales internos, el Tribunal Constitucional ha sentenciado que las bases del régimen jurídico estatales tienen que respetar siempre "las posibilidades de organización propia de las Comunidades Autónomas que se derivan del principio de autonomía organizativa" (STC 204/1992, de 26 de noviembre). Es decir, según la doctrina del alto

9 Colom Pastor, B. (2001): Veinticinco años de autonomía balear, Marcial Pons, Govern de les Illes Balears, Universitat de les Illes Balears.

10 Mora Martí, B. (2008): “Disposición transitoria primera. Comisión Mixta de Transferencies”, A. Blasco Esteve (dir.), Comentarios al Estatuto de Autonomía de las Islas Baleares, Thomson-Civitas, págs. 1465-1476.

11 Cabotà Sainz, P. (2008): “Artículo 31.1. "Régimen jurídico y sistema de responsabilidad de la Administración de la Comunidad Autónoma”", A. Blasco Esteve (dir.), Comentarios al Estatuto de Autonomía de las Islas Baleares, Thomson-Civitas, págs. 498-502. 
Tribunal, el alcance de las bases es de mayor intensidad en relación con la potestad de regulación de la parte institucional y externa de la organización, pero de menor intensidad cuando se trata de la potestad de organización interna en sentido estricto.

No hay que olvidar, además, que el artículo 103.1 de la Constitución de 1978, cuando establece los principios que conforman el modelo de organización de la Administración pública española, obliga a la Administración a servir con objetividad los intereses generales y a actuar de acuerdo con los principios de eficacia, jerarquía, descentralización, desconcentración y coordinación, con sumisión plena a la ley y al Derecho. De aquí se deriva no tan sólo el principio básico de legalidad de la Administración y del poder ejecutivo (arts. 9, 25.1, 103.1, 105, 106, 152 y 153) sino también los principios que tienen que presidir la organización de cualquier Administración Pública.

En cumplimento del mandato estatutario de atribución de potestad organizativa, un año y ocho meses después de haberse promulgado el Estatuto de 1983, el Parlamento de las Islas Baleares aprueba la Ley 5/1984, de 24 de octubre, de régimen jurídico de la Administración de la Comunidad Autónoma de las Islas Baleares, que regula conjuntamente la personalidad jurídica y los órganos de la Administración de la Comunidad, el Presidente de la Comunidad, la competencia y el funcionamiento de los órganos superiores de la Comunidad y el régimen jurídico. Otros ámbitos específicos de la organización administrativa, o relacionados con ella, fueron regulados también en la década de los ochenta y parte de los noventa: la Administración institucional de la Comunidad Autónoma, mediante la Ley 3/1989, de 29 de marzo, de entidades autónomas y empresas públicas y vinculadas; el control de la actividad del sector público, por la Ley 1/1987, de 18 de febrero, de la Sindicatura de Cuentas; el personal al servicio de la Administración, a través de la Ley 2/1989, de 22 de febrero, de función pública; la gestión económica de la Administración, por la Ley 1/1986, de 5 de febrero, de finanzas; la normalización lingüística en las Islas Baleares, mediante la Ley 3/1986, de 29 de abril; el patrimonio de la Comunidad Autónoma, por la Ley 11/1990, de 17 de octubre; la regulación de los Consejos Insulares, mediante la Ley 5/1989, de 13 de abril; la regulación del Consejo Consultivo, por la Ley 5/1993, de 15 de junio; y la aprobación del régimen de incompatibilidades de los miembros del Gobierno y de los altos cargos, mediante la Ley 2/1996, de 19 de noviembre.

Con posterioridad, durante la década de los años noventa hay una reforma de la legislación estatal administrativa e institucional de gran alcance (Segura, 2004) ${ }^{12}$, ocasionada básicamente por los cambios en la normativa a raíz de las disposiciones previstas en la Ley 30/1992, de 26 de noviembre, de Régimen Jurídico de las Administraciones Públicas y del Procedimiento Administrativo Común (en adelante, LRJPAC), la Ley 6/1997, de 14 de abril, de Organización y Funcionamiento de la Administración General del Estado (en adelante, LOFAGE), la Ley 50/1997, de 27 de noviembre, del Gobierno, así como también por la evolución del aparato organizativo interno de la Comunidad. Esta reforma da pie a la aprobación de dos leyes organizativas fundamentales del poder ejecutivo autonómico, una específica de regulación de la cúpula política -Gobierno y Presidente-, y otra de regulación de la estructura administrativa, que derogan la primera Ley de régimen jurídico de 1984: la Ley 4/2001, de 14 de marzo, del Gobierno (en adelante, LGOB), y la Ley 3/2003, de 26 de marzo, de régimen jurídico de la Administración de la Comunidad Autónoma (en adelante, LRJACA).

Debe darse cuenta también de toda una serie de reformas legislativas importantes realizadas durante la primera década del siglo XXI, relacionadas con la Administración de la Comunidad: la reforma de la Ley de la Sindicatura de Cuentas de 1987, por la Ley 4/2004, de 2 de abril; de la Ley del personal al servicio de la Administración de 1989, por la Ley 3/2007, de 27 de marzo, de función pública; de la Ley de finanzas de 1986, mediante el Decreto legislativo 1/2005, de 24 de junio, por el cual se aprueba el texto refundido en esta materia; de la Ley del patrimonio de la Comunidad de 1990, mediante la Ley 6/2001, de 11 de abril; de la Ley de los Consejos Insulares de 1989, a través de la Ley 8/2000, de 31 de mayo; de la Ley del Consejo Consultivo de 1983, por la Ley 5/2010, de 16 de junio; y de la Ley reguladora de los entes institucionales de 1989, mediante la Ley 7/2010, de 21 de julio, del sector público instrumental. Cabe añadir, además, la regulación de las subvenciones, primero, a través de la Ley 10/2000, de 30 de noviembre, y después, mediante el Decreto legislativo 2/2005, de 28 de diciembre; y la regulación del Consejo Económico y Social, mediante la Ley 10/2000, de 30 de noviembre (reformada por la Ley 5/2009, de 17 de junio). Tras la aprobación del EAIB de 2007, el Parlamento de las Islas Baleares aprueba un cuerpo normativo nuevo de extracción estatutaria. Por un lado, la regulación de la Agencia Tributaria, mediante la Ley 3/2008, de 14 de abril [esta Ley, junto con la Ley 5/2009, de 17 de junio (Consejo Económico y Social) y la Ley 5/2010, de 16 de junio (Consejo Consultivo), se integra en lo que podría denominarse el "bloque estatutario institucional”. Por otro lado, dentro del que podría llamarse "bloque estatutario audiovisual”], la creación y regulación del Consejo Audiovisual, mediante la Ley 2/2010, de 7 de junio, del Ente público de Radiotelevisión de las Islas Baleares, mediante la Ley 15/2010, de 22 de diciembre, y la regulación de la publicidad institucional, mediante la Ley 13/2010, de 9 de diciembre. En

12 Segura Ginard, LL. (2004): “Notes sobre organització a la nova llei de règim jurídic de l'Administració balear”, Revista jurídica de les Illes Balears, 2, págs. 167-179. 
tercer lugar, la innovadora normativa relativa a la buena administración y al buen gobierno, mediante la Ley 4/2011, de 30 de noviembre; esta ley, junto con la Ley 7/2010, de 21 de julio, del sector público instrumental, antes citada, configura lo que se denominaría el "bloque normativo estatutario de integridad". Finalmente, debe destacarse la modificación de la LGOB y de la LRJACA, mediante la Ley 12/2010, de 12 de noviembre, para su adaptación a la Directiva 2006/123/CE del Parlamento Europeo y del Consejo, de 12 de diciembre de 2006, relativa a los servicios en el mercado interior.

\section{LA ADMINISTRACIÓN DE LA COMUNIDAD AUTÓNOMA DE LAS ISLAS BALEARES}

\section{Principios básicos de la organización}

El artículo 152, apartado 1, de la Constitución establece un esquema organizativo básico de las comunidades autónomas que ha sido atendido por el Estatuto de Autonomía de las Islas Baleares -así como también por todos los demás-, según el cual la organización institucional autonómica se basa fundamentalmente en el Parlamento, el Gobierno y el Presidente de la Comunidad Autónoma. El Presidente y los miembros del Gobierno responden políticamente ante la asamblea legislativa -por el hecho que la Constitución diseña un sistema de relación entre poderes (legislativo y ejecutivo) típicamente parlamentario-, y el Gobierno asume funciones ejecutivas y administrativas típicas, ejerce la potestad reglamentaria y dirige la Administración (art. 97 CE y art. 15 LGOB). En las Islas Baleares, este esquema organizativo se ha visto ampliado por la incorporación dentro del sistema institucional autonómico de los Consejos Insulares de Mallorca, Menorca, de Ibiza y de Formentera (art. 39 EAIB de 2007), que ha supuesto una fragmentación del poder ejecutivo autonómico, como veremos más adelante.

El sistema organizativo que prevé el Estatuto de Autonomía responde a las exigencias que se derivan del principio de Estado democrático (art. 1.1 CE), de las que obviamente la Administración de la Comunidad Autónoma no puede escaparse. Como ha destacado Santamaría Pastor (2009) ${ }^{13}$, el primer requerimiento que el principio democrático impone a la Administración es, más allá de su subordinación al poder legislativo, su configuración como estructura burocrática de apoyo directo al órgano supremo ejecutivo en su tarea de la gobernación. La posición supraordenada del Gobierno respecto de la Administración determina la atribución a aquél de un poder de dirección sobre ésta, tal como viene establecido en el artículo 97 CE ("El Gobierno dirige... la administración civil y militar") y confirmado en el artículo 3.3 LRJPAC ("Bajo la dirección del Gobierno de la Nación, de los órganos de gobierno de las comunidades autónomas y de los correspondientes de las entidades que integran la administración local, la actuación de la administración pública respectiva se desarrolla para lograr los objetivos que establecen las leyes y el resto del ordenamiento jurídico"). En el ámbito de la Comunidad Autónoma, así viene declarado tanto en el artículo 15.1 de la LGOB ("el Gobierno, de acuerdo con las directrices del presidente, establece la política general y dirige la Administración de la Comunidad Autónoma”) como en el artículo 5.2 de la LRJACA ("bajo la dirección superior del presidente y del Gobierno, la Administración de la Comunidad Autónoma se estructura en órganos superiores y órganos directivos"). Este poder de dirección del Gobierno, derivado de la posición vicarial o servicial de la Administración, supone dos tipos de consecuencias: desde una perspectiva negativa, que la Administración es algo más que un simple brazo extensivo y ejecutor del Gobierno, puesto que dispone de un cierto nivel de funcionamiento autónomo y de margen de libertad para decidir los medios técnicos más adecuados para la consecución de los fines que el Gobierno estime oportunos; desde una perspectiva positiva, en cambio, el poder de dirección implica que el Gobierno retiene una potestad de fijación del marco de los objetivos (generales y concretos) que la Administración tiene que perseguir, así como de adopción de todas las decisiones que aseguren el cumplimiento de estos objetivos, como por ejemplo aquellas relacionadas con la planificación de la actividad administrativa, la fijación de directivas vinculantes de orientación de la actividad administrativa o la exigencia de responsabilidad en caso de inobservancia de las directivas, actuación ineficaz o apartamiento de la legalidad (Santamaría Pastor, 2009: 80). Como vemos, el Gobierno y la Administración de la Comunidad Autónoma encarnan el poder ejecutivo. Y todavía más, el Gobierno tiene una doble condición o naturaleza, puesto que, por un lado, es la institución de autogobierno u órgano estatutario de naturaleza política, pero, por otra, es el órgano colegiado superior de dirección de la Administración, es decir, órgano de naturaleza administrativa. La naturaleza política del Gobierno deriva principalmente de su consideración como institución de autogobierno de extracción constitucional y estatutaria subordinada al poder legislativo; en cambio, su naturaleza administrativa como órgano típico incorporado en la estructura de la Administración de la Comunidad Autónoma se deduce de varios preceptos normativos, como por ejemplo los artículos 22.2, 42, 54.1 y 58.3 de la LRJACA (Segura, 2004), que confirman que se trata de un órgano sometido a reglas típicas del régimen administrativo de las administraciones públicas.

Aun así, la concentración del poder ejecutivo en manos del Gobierno y de la Administración de la Comunidad Autónoma se ha visto alterada por la irrupción de la figura de los Consejos Insulares dentro del sistema institu-

13 Santamaría Pastor, J. A. (2009): Principios de Derecho Administrativo General I, $2^{\text {a }}$ ed., lustel, Madrid, p. 79. 
cional autonómico, hasta el punto que éstos son también auténtico poder ejecutivo (arts. 58.1 y 84.2 EAIB 2007). Esta alteración, lejos de ser extraña, es totalmente coherente con uno de los valores superiores del ordenamiento jurídico español, el pluralismo (art. 1.1 CE), que, como ha dicho Santamaría Pastor (1999: 52), es el "trasunto axiológico de la idea de Estado democrático". Del pluralismo se deriva una regla básica de actuación y de organización de la Administración, el principio de descentralización (art. 103.1 CE), que, junto con otros como el de desconcentración o el de participación, representa el momento de la distribución del poder ejecutivo (Idem, 1988: 243) el sentido que cada una de las administraciones superiores o comunitarias tiene que ejercer descentralizadamente sus competencias propias a través las administraciones inferiores (insulares y locales). Esta actuación, según ha explicado el citado autor (Ibidem: 244-245), se realiza mediante un doble camino: por un lado, confiriendo a las administraciones inferiores el nivel de participación en el ejercicio de las competencias propias que sea adecuado para la gestión de los intereses de cada una de las administraciones; y, por otra, confiando a las administraciones inferiores la gestión concreta de las potestades administrativas -que, por su naturaleza, no exigen una gestión centralizada-, a través de la transferencia o delegación.

Este es precisamente el modelo de administración descentralizada o indirecta (Colom, 2001:114) que propugna el ordenamiento de la Comunidad Autónoma de las Islas Baleares, tanto el Estatuto de Autonomía de 1983, pero sobre todo el de 2007 (arts. 8, 39, 50.6, 58.1, 70, 71, 72, 73, 75.6, 80, 84.2, 85.3, DA 3 $3^{\text {a }}$, EAIB 2007), como la LRJACA de 2003 (art. 4). De entrada, el artículo 8 del Estatuto vigente señala que la Comunidad Autónoma articula su organización territorial en islas y en municipios, y que las instituciones de gobierno de las islas son los consejos insulares, y las de los municipios, los ayuntamientos. Por otro lado, el artículo 80 del Estatuto de 2007 -y en el mismo sentido, y con mejor redacción técnica, el artículo 42 del Estatuto de 1983 (Segura)-, dispone que la Administración de la Comunidad Autónoma ejerce sus funciones mediante los entes y los organismos que dependen del Gobierno, así como a través de las islas (tanto la versión de 2007 como la de 1983 emplea de manera desafortunada la expresión "consejos insulares" en lugar de "islas") y de los municipios. Por su parte, el artículo 4 de la LRJACA, cuando se refiere a la estructura territorial de la Administración de la Comunidad Autónoma, además de la existencia de órganos con competencia central, prevé que "cuando las características de la materia lo exijan, y de acuerdo con el mecanismos legalmente previstos, los consejos insulares y los municipios tienen que asumir, en el ámbito territorial establecido, las facultades ejecutivas correspondientes a competencias de la Administración autonómica".

Según este modelo de administración indirecta o descentralizada, como se ha escrito, la Administración de la Comunidad ejerce altas funciones, entre las que destacan las relativas en la planificación, la coordinación, el ejercicio de la potestad reglamentaria general y de la actividad de fomento en las competencias del Gobierno, la representación en frente del Estado o el otorgamiento de determinadas autorizaciones, de modo que la relación ordinaria con la ciudadanía, así como la mayor parte de las funciones ejecutivas, pasa a estar más bien en manos de los entes insulares y, en menor medida, de los municipales, con independencia de la titularidad de las competencias afectadas [Colom (2001:115), Segura (2008b)]. Paralelamente, la Administración también ejerce sus funciones administrativas mediante entes instrumentales o filiales de distinto carácter y naturaleza, que se crean por la necesidad -a efectos de una mayor eficacia- de descentralización funcional del aparato organizativo, con el objetivo de tener centros de decisión y de responsabilidad más inmediatos y cercanos a los ciudadanos, y con el propósito de escape de las exigencias que imponen el Derecho administrativo y el Derecho financiero, a los efectos de facilitar una actuación más ágil (Socias/Trías, 2008)².

\section{Tipología de órganos}

Prácticamente todas las comunidades autónomas se han dotado de un modelo de organización equivalente al modelo propio del Estado, basado por lo tanto en una organización central y una serie de servicios territoriales o periféricos. Hay que destacar la peculiaridad de la Comunidad Autónoma de las Islas Baleares como consecuencia de la existencia de los Consejos Insulares, y de las importantes competencias que ostentan de acuerdo con las previsiones del Estatuto de Autonomía, que ha provocado que la estructura periférica haya sido substituida desde el primer momento por la organización insular -con alguna contada excepción en el departamento de Educación-, en clara consonancia con el principio de descentralización. Otros principios de actuación, como el de eficacia, jerarquía, desconcentración, coordinación y legalidad, se imponen también a la actuación de la Administración autonómica (art. 3 LRJACA), en términos homologables a los que se observan en la Administración estatal y en la organización autonómica comparada.

Según la LRJACA (arts. 5 y 6), la organización administrativa situada bajo la dirección superior del presidente y del Gobierno está integrada por: i) órganos superiores (consejeros), que tienen que "establecer los planes

14 Santamaría Pastor, J. A. (1988): Fundamentos de Derecho Administrativo I, Centro de Estudios Ramón Areces, Madrid.

15 Sobre este tema puede verse Socias Camacho, J. M., Trías Prats, B. (2008): Administració institucional. Consideracions generals i règim del ens de la Comunitat Autònoma de les Illes Balears, Tirant lo Blanch, Valencia. 
de actuación de la organización situada bajo su responsabilidad"; ii) órganos directivos (secretarios generales, directores generales y los otros órganos a los cuales se asimilen en rango), que les "corresponde la ejecución y el desarrollo de los planes de actuación"; y iii) demás órganos y unidades administrativas inferiores. Hay que advertir, como ha apuntado la doctrina, la influencia decisiva de la LOFAGE a la hora de asignar formalmente a los consejeros como órganos superiores de la Administración -y no al Gobierno, a quien le corresponde la función de dirigir a la Administración-. Esta función directiva de carácter político no es contradictoria con la naturaleza administrativa que tiene el Gobierno, como se ha visto; y el hecho que éste no sea formalmente órgano superior de la Administración no impide que pueda ser realmente considerado como órgano de dirección superior con posición predominante sobre los órganos superiores y directivos.

La Administración autonómica, siguiendo la senda estatal, se organiza de acuerdo con los principios de dirección política, jerarquía y gestión burocrática, en base a una división departamental -las consejerías-, a quien "corresponde el desarrollo de uno o de varios sectores de actividad administrativa funcionalmente homogéneos" (art. 7 LRJACA). Los consejeros o titulares de las consejerías son, a la vez, miembros del Gobierno y máximos responsables del correspondiente departamento, y por eso "dirigen y gestionan la actividad administrativa de la consejería en los sectores correspondientes y asumen la responsabilidad inherente a esta dirección" (art. 9 LRJACA). Internamente, la estructura de las consejerías también es en gran medida parecida a la propia de los departamentos ministeriales, si bien bastante más simplificada. Así, hay que distinguir dos categorías orgánicas, jerárquicamente subordinadas a la figura del consejero [(art. 10.1. d) y f)], pero entre ellas regidas por una relación de competencia: i) secretario general, que tiene asignados los servicios comunes de toda la consejería y también las funciones de asesoramiento jurídico y de apoyo técnico (art. 13 LRJACA); ii) director general, encargado de la gestión de una o de varias áreas funcionalmente homogéneas de cada consejería (art 15 LRJACA). Podemos advertir que el legislador ha descartado la figura del viceconsejero, previsto en buena parte de las comunidades autónomas, equiparable a la figura del subsecretario estatal como órgano intermedio entre los órganos superiores y los directivos. Por debajo de esta organización se situarían finalmente los diferentes órganos y unidades administrativas inferiores; siguiendo el criterio de la LOFAGE (art. 5.2), los órganos son "aquellas unidades administrativas a las que se les atribuyan funciones que tengan efectos jurídicos frente a terceros, o cuya actuación tenga carácter preceptivo" (art. 6.3 LRJACA); las unidades administrativas "son elementos organizativos básicos de la estructura orgánica y comprenden el lugar de trabajo vinculados funcionalmente por razón de sus cometidos a un mando superior común" (art. 6.1 LRJACA).

Como vemos, los órganos fundamentales y necesarios de cada consejería son el secretario general y los directores generales, que conforman una estructura orgánica básica que se tiene que aprobar por decreto del Presidente del Gobierno, en virtud con lo que dispone la Ley del Gobierno y la Ley de régimen jurídico de la Comunidad. Los consejeros tienen que desarrollar la organización básica mediante orden, de acuerdo con la relación de puestos de trabajo vigente, con el objeto de determinar las funciones atribuidas a las unidades administrativas de cada consejería (arts. 6.4 y 8 LRJACA). Además de un secretario general (art. 13.2 LRJACA) y de varios directores generales, la consejería también puede contar con otros órganos directivos asimilados en rango (art. 5.4 LRJACA), como es el caso de la dirección de la Abogacía (art.70.2 LRJACA). Los titulares de la secretaría general y de las direcciones generales son nombrados y separados por decreto del Gobierno, a propuesta del titular de la Consejería, atendiendo a criterios de competencia profesional y de experiencia, y con responsabilidad personal por la gestión desarrollada y sujeción a control del órgano superior competente (arts. 12.1, 13.2 y 15.2 LRJACA). El titular de la dirección de la Abogacía es un caso especial, puesto que, según el artículo 70.2 LRJACA, su titular tiene que ser un funcionario público del cuerpo de abogados del Estado o del cuerpo superior de abogados de la Administración de la Comunidad Autónoma, y su nombramiento no se realiza por decreto del Gobierno.

Bajo esta estructura política -órganos superiores y directivos- se sitúa la estructura administrativa, formada por órganos -distintos de los que acabamos de ver - y unidades administrativas. La creación de estos órganos (art. 6.4 LRJACA) se realiza en virtud de lo que dispone la normativa estatal básica en el artículo 11 de la LRJPAC ("determinación de su forma de integración en la Administración... y de su dependencia jerárquica", "delimitación de sus funciones y competencias" y "dotación de los créditos necesarios por su puesta en marcha y para su funcionamiento"), de acuerdo con las previsiones concretas que establece la legislación autonómica en los artículos 17, 18 y 19 de la LRJACA. Así, por ejemplo, hay que subrayar la necesidad de norma específica para la creación de los órganos, en el supuesto de que se atribuyan funciones decisorias, de propuesta, de emisión de informes o de seguimiento de control de otros órganos (art. 19.1 LRJACA); mientras que si los órganos realizan exclusivamente funciones consultivas internas o de asesoramiento y de consulta no preceptiva, se pueden crear por convenio, por acuerdo de Consejo de Gobierno o por resolución de la consejería interesada (art. 19.2 LRJACA).

En cuanto a las unidades administrativas, éstas se estructuran de manera jerárquica en departamentos, servicios, secciones y negociados, y su creación, modificación o supresión se hace a través de las relaciones de puestos 
de trabajo [art. 6, apartado 2) y 5)]. Las diferencias entre departamentos y servicios, como ha apuntado Segura (2004), suelen ir más ligadas a criterios de relevancia o de carácter retributivo que a razones vinculadas con las responsabilidades de gestión. Para acabar, hay que destacar, tal como prevé el artículo 6.6 de la LRJACA, que "el inicio del funcionamiento de nuevas unidades previstas en la relación de puestos de trabajo sólo será efectivo cuando se hayan establecido reglamentariamente las funciones que tienen que desarrollar".

\section{Tipología de entes instrumentales}

La regulación de la tipología de entes que constituyen la Administración instrumental estatal se contiene en LOFAGE (Título III y Disposición adicional duodécima), en la Ley 28/2006, de 18 de julio, de Agencias estatales para la mejora de los servicios públicos, y en la Ley 50/2002, de 26 de diciembre, de Fundaciones (capítulo XI). En cuanto al ámbito autonómico balear, la competencia legislativa la tiene la Comunidad Autónoma, de acuerdo con la Constitución y el Estatuto de Autonomía de las Islas Baleares de 2007 (Disposición adicional tercera) ${ }^{16}$. La novedad más destacable del vigente Estatuto de Autonomía es que establece una reserva material de ley en relación con el ejercicio de la potestad organizativa instrumental autonómica, tal como también lo hace el Estatuto de autonomía de Cataluña de 2006. Por primera vez - puesto que ni la Constitución ni el anterior Estatuto de Autonomía balear de 1983 lo preveían- se reserva al Parlamento la decisión de regular una organización concreta instrumental de la que se pueda inferir un modelo de administración. Con anterioridad, había una reserva formal de Ley -desde la promulgación de la Ley de entidades estatales autónomas de 26 de diciembre de 1958 pasando por la Ley 3/1989, de 29 de marzo, de entidades autónomas y empresas públicas y vinculadas a la Comunidad Autónoma-, pero sin embargo, en la actualidad, la tipología de entes instrumentales dependientes de la Comunidad está reservada estatutariamente al legislador autonómico. El Parlamento de las Islas Baleares, aprovechando la ocasión que le brinda el Estatuto de autonomía de 2007, ha aprobado una nueva ley de organización de este organización especializada, la Ley 7/2010, de 21 de julio, del sector público instrumental de Comunidad Autónoma de las Islas Baleares, que ha aportado racionalidad, claridad y coherencia en un ámbito que se ha caracterizado por la complejidad, la dispersión, la fragmentación, el sobredimensionamiento (el boom de creación de estos tipos de entidades, sobre todo las de naturaleza privada, empieza a intensificarse a partir del año 2000) e, incluso, en algunas ocasiones, el abuso de poder, como se ha demostrado a nivel judicial.

En origen, la regulación que ha permitido la creación de entes institucionales se contenía en la Ley 3/1989, de 29 de marzo, antes citada ${ }^{17}$. Junto a las categorías de entes institucionales previstos en esta Ley, debía tenerse en cuenta también las denominadas fundaciones del sector público, de proliferación creciente en la Comunidad Autónoma, y que se insertan en una categoría que surge originariamente de la mano del legislador económico estatal (Ley 47/2003, de 26 d noviembre, general presupuestaria), categoría que finalmente es asumida por el legislador balear en 2005. El Decreto legislativo 1/2005, de 24 de junio, por el que se aprueba el Texto Refundido de la Ley de Finanzas, incluye por primera vez las fundaciones de sector público autonómico en la categoría general de sector público de la Comunidad. Por último, en contraste con el conjunto de entes propiamente institucionales (entidades de la Ley 3/1989, de 29 de marzo, y fundaciones del sector público del Decreto legislativo 1/2005, de 24 de junio), existe la figura del consorcio, personificación instrumental de carácter corporativo, cuya regulación en el ámbito autonómico balear aparece contenida en el artículo 85 de la Ley 3/2003, de 26 de marzo, de Régimen Jurídico de la Administración de la Comunidad Autónoma de las Islas Baleares. Finalmente, la Ley 3/1989, de 29 de marzo, ha sido derogada en su totalidad por la Ley 7/2010, de 21 de julio, antes citada.

Las causas que han originado la creación de entes instrumentales de distinto carácter y naturaleza responde, entre otros, a dos factores que hay que destacar. Por un lado, a la necesidad -a efectos de una mayor eficaciade descentralización del aparato organizativo, desde el momento en que éste asume una cierta dimensión, con el objetivo de crear centros de decisión y de responsabilidad más inmediatos y cercanos a los ciudadanos. Y, por otro, al propósito de escape de las exigencias que imponen el derecho administrativo y el derecho financiero, a los efectos de facilitar una actuación más ágil. El origen de este fenómeno, conocido como "huida al derecho privado" se sitúa en la disociación entre forma de las organizaciones y régimen regulador de su funcionamiento y actividad. Esta distorsión de la ecuación entre forma de personificación y régimen jurídico aplicable se ha manifestado de forma intensa en los entes que conforman la Administración instrumental. Efectivamente, el descuido por cuestiones referentes a la status de la Administración pública (noción que define la personalidad y la capacidad) o al régimen de la potestad de organización de la actuación administrativa, ha permitido la libertad de elección de formas de actuación y de organización de las actividades, en virtud del que se ha denominado desconexión entre

16 Véase Socias Camacho, J. M. (2008): “Disposición adicional tercera. Entidades y organismos para prestar servicios (I. Administración instrumental autonómica)”, A. Blasco Esteve (dir.), Comentarios al Estatuto de Autonomía de las Islas Baleares, Thomson-Civitas, págs. $1425-1435$.

17 Sobre la regulación prevista en esta Ley, es imprescindible Blasco Esteve, A. (1994): “La Administración institucional de la Comunidad Autónoma de las Islas Baleares", en VV.AA., Administración Instrumental (Libro homenaje a Manuel Francisco Clavero Arévalo), Tomo II, Civitas/ Instituto García Oviedo (Universidad de Sevilla), Madrid. 
la status subjetivo de la Administración -como organización- y el régimen objetivo de la actividad. El dogma de la libertad de elección de las formas de organización de la actividad administrativa ha provocado un amplio debate a la doctrina administrativa, debate que se ha visto intensificado por la privatización formal lograda a partir del sometimiento de los entes públicos a formas privadas.

La nueva Ley 7/2010, de 21 de julio, del sector público instrumental (en adelante, LSP) ${ }^{18}$, hace una clasificación y regulación del conjunto de los entes instrumentales según su naturaleza y lleva a cabo una adaptación sistemática de los entes existentes en el momento de su entrada en vigor a las nuevas categorías establecidas en la ley. El ámbito de la norma incluye tres grandes grupos de personificaciones jurídicas que, con independencia de su sometimiento al régimen jurídico público o privado, quedan encuadrados en el concepto genérico de sector público instrumental. El primero de los grupos recoge los “organismos públicos” (regulados en el Título I de la LSP), es decir, los organismos autónomos y las entidades públicas empresariales. En este punto, hay que destacar la ausencia de la figura de las agencias —introducida en la LOFAGE por la Ley 28/2006, de 18 de julio, de agencias estatales para la mejora de los servicios públicos-, porque en el ámbito de la Comunidad Autónoma se considera "adecuado" y "suficiente" -a tenor del Preámbulo de la Ley- el marco jurídico que ofrecen las otras dos figuras típicas que se han indicado. El segundo grupo, relativo a las personificaciones jurídico privadas, se denomina "organismos de naturaleza privada de titularidad pública" (incluidos en el Título II de la LSP), y está integrado por las sociedades mercantiles públicas y las fundaciones del sector público de la Comunidad Autónoma, esto es, entidades en que ésta tiene, directamente o indirectamente, la mayoría de capital social o de la dotación, respectivamente. Finalmente, un tercer grupo recoge por primera vez la regulación de los “consorcios" que tienen que someter su régimen jurídico al ordenamiento público autonómico (previstos en el Título III de la LSP). La regulación de estos consorcios se efectúa, en todo caso, de manera separada de los organismos públicos típicos, atendida la naturaleza peculiar — corporativa de base asociativa — y la configuración — esencialmente estatutaria — de este tipo de ente.

Cabe poner de relieve que, a diferencia de la LOFAGE -que adolece del importante déficit de no hacer referencia alguna

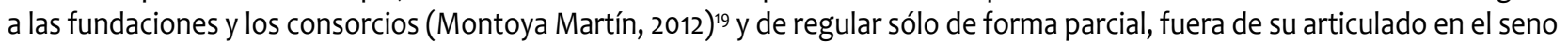
de una disposición adicional, a las sociedades-, la Ley balear 7/2010, de 21 de julio, tiene la virtud de concentrar en un solo cuerpo legal el conjunto de entes instrumentales del sector público autonómico, tanto los de naturaleza institucional como los de naturaleza corporativa-asociativa, y tanto los de personificación pública como privada.

El Título Preliminar de la LSP contiene un cuerpo muy relevante de disposiciones generales que contienen medidas de control de la actividad de los distintos entes instrumentales del sector público autonómico -que analizaremos con un poco más de detalle en seguida- referido a los requerimientos previos a su creación, a su régimen económico-financiero en todas sus vertientes - presupuestario, de tesorería y endeudamiento, contable y de control interno-, a los órganos de dirección y recursos humanos, al régimen en materia de contratación y de patrimonio. Entre las disposiciones generales hay que destacar las medidas tendentes a racionalizar la utilización del abanico de entes instrumentales y a limitar el gasto público, como son la necesidad de elaborar, en todo caso y con carácter previo a la creación del ente, un plan de actuación inicial y un estudio económico-financiero. Además, y sin perjuicio del régimen general de control financiero que prevé la legislación de finanzas, merece una mención especial los mecanismos supervisores que la Ley establece (como los comités de auditoría financiera o los planes de actuaciones en el ámbito del control de eficacia y eficiencia) así como las nuevas medidas de control del gasto (como las auditorías internas o los controles permanentes). Pasemos de inmediato a analizar con más detenimiento la tipología de entes instrumentales prevista en la nueva Ley del sector público de 2010.

\section{Organismos autónomos}

Se tienen que crear por ley del parlamento autonómico, que debe determinar el tipo de organismo que crea, con la indicación de sus finalidades generales; las funciones, las competencias y las potestades administrativas generales que pueda ejercer; la consejería a la que inicialmente se adscribe; los recursos económicos y las particularidades de su régimen de personal, de contratación, patrimonial, económico-financiero; la existencia de un presupuesto propio e independiente del presupuesto de la Administración de la Comunidad Autónoma o, en su defecto, de un presupuesto integrado en el de la Administración de la Comunidad Autónoma; y, finalmente, en caso que sea necesario, el reconocimiento expreso de una especial autonomía o independencia funcional del ente respecto de la Administración de la Comunidad Autónoma por razón de las funciones que tiene que ejercer el ente.

18 Esta Ley ha sido modificada, primero, mediante el Decreto-Ley 1/2011, de 29 de julio, de modificación del artículo 20.3 de la Ley $7 / 2010$, de 21 de julio, del sector público instrumental de la Comunidad Autónoma de las Islas Baleares, y después, mediante la Disposición final novena de la Ley $9 / 2011$, de 23 de diciembre, de presupuestos generales de la Comunidad Autónoma de las Islas Baleares para el año 2012. En el momento de revisar las pruebas de este artículo se observa que esta Ley $7 / 2010$ ha sufrido otras modificaciones, de las que no vamos a tratar por falta de espacio y tiempo.

19 Montoya Martín, E. (2012): “Reflexiones sobre el sector público instrumental en un contexto de crisis económica: la inaplazable hora de la racionalización” (mimeo), en VII Congreso Asociación Española de Profesores de Derecho Administrativo, Tarragona. 
En cuanto al personal, puede ser funcionario o laboral, en los términos previstos en la normativa reguladora de la función pública de la Comunidad Autónoma. Al personal le es aplicable la legislación autonómica de función pública, en los mismos términos establecidos para el personal al servicio de la Administración de la Comunidad Autónoma, sin perjuicio, como ya se ha dicho, que la ley de creación pueda establecer determinaciones específicas en cuanto al régimen de personal (art. 39 LSP).

El Consejo de Gobierno tiene que aprobar el proyecto de ley de creación del organismo, a propuesta de la consejería de adscripción. A la propuesta se tiene que adjuntar, entre otros documentos, el proyecto de estatutos del organismo, el plan de actuación inicial y el informe económico-financiero. La consejería competente en materia de hacienda y presupuestos tiene que emitir un informe preceptivo sobre la propuesta de aprobación y la documentación que se adjunta. (art. 34 LSP).

Se trata, en síntesis, de entidades que gozan de potestades administrativas y que se rigen por el derecho público, sin perjuicio, sin embargo, de la capacidad de actuar según el Derecho privado, que tienen como todos los entes públicos. El régimen jurídico general de estas entidades está formado, por tanto, por el amplio conjunto de reglas y principios que conforman el Derecho administrativo (arts. 29 y 38 LSP).

\section{Entidades públicas empresariales}

Una de las novedades de la LSP es que prevé que la creación de las entidades públicas se tiene que hacer por ley (con la Ley 3/1989, de 29 de marzo, bastaba que la ley autorizara su creación). La ley de creación tiene que determinar básicamente los mismos aspectos que los previstos para la creación de los organismos autónomos, antes mencionados. El Consejo de Gobierno tiene que aprobar el proyecto de ley de creación a propuesta de la consejería de adscripción, de acuerdo con el procedimiento previsto para la creación de los organismos autónomos, visto más arriba (art. 34 LSP).

La ley de creación puede establecer particularidades en relación a su régimen presupuestario, económicofinanciero, de contabilidad, intervención y control, siendo aplicable en su defecto el régimen general que prevé la propia LSP y la legislación de finanzas de la Comunidad Autónoma. En cuanto al personal, puede ser laboral propio, funcionario de la Administración de la Comunidad Autónoma o de los organismos autónomos a los que se adscriba, o funcionario de cualquier Administración pública que se incorpore por cualquier procedimiento de provisión o de ocupación de lugares de trabajo, de acuerdo con la normativa de función pública de la Comunidad (art. 44 LSP).

Se trata, pues, de entidades que se rigen por el Derecho público en la formación de la voluntad de sus órganos, en el ejercicio de las potestades administrativas que tengan atribuidas y en aquello que prevea la propia Ley del sector público instrumental u otra norma con rango de ley (por ejemplo, contratación, finanzas o patrimonio) o los estatutos de la entidad. En el resto de los aspectos, se rigen por el Derecho privado (art. 42 LSP).

\section{Sociedades mercantiles públicas}

Como sabemos, la LSP regula, dentro de la categoría de "organismos de naturaleza privada de titularidad pública", las sociedades mercantiles con participación mayoritaria en el capital social de la Comunidad Autónoma, ya sea directa o indirecta. Estas sociedades se equipararían a las sociedades mercantiles estatales, incluidas dentro de la categoría doctrinal de personificaciones instrumentales privadas, las cuales en ningún caso pueden ejercer potestades administrativas (art. 48 LSP). La creación de las sociedades de participación mayoritaria pública y las eventuales modificaciones de la escritura pública de constitución, como también los actos de adquisición o de pérdida de la posición mayoritaria, directa o indirecta, de la Comunidad Autónoma y la extinción de la entidad, no requieren decreto del Consejo de Gobierno, tal como preveía antes la Ley 3/1989, de 29 de marzo, sino que es suficiente acuerdo previo del Consejo de Gobierno (art. 52 LSP). Los estatutos de las sociedades mercantiles públicas se tienen que elevar al Consejo de Gobierno, junto con la propuesta de acuerdo por el que se autoriza la creación (art. 53 LSP).

Con carácter general, estas entidades se rigen por el ordenamiento jurídico privado (arts. 24, 49, 50, 51), salvo las materias en que sea aplicable la normativa económico-financiera -a los efectos de verificar en todo caso los principios generales de economía, eficacia y eficiencia, en el marco de una correcta gestión financiera de los recursos públicos-, y la de contratación ${ }^{20}$. Por lo que al personal se refiere, la Disposición adicional primera de la Ley estatal 7/2007, de 12 de abril, del Estatuto básico del empleado público, prevé que para las entidades del sector público no incluidas en el artículo 2 de la Ley -sociedades y fundaciones- sólo son de aplicación los principios básicos que contienen los artículos 52, 53, 54, 55 y 59 de la Ley 7/2007 (deberes, código de conducta y principios generales de acceso).

20 Sobre la evolución de la sumisión de sociedades y fundaciones a la normativa económico-financiera y de contratación, Socias Camacho, J. M. (2006): Fundaciones del sector público. En especial el ámbito sanitario, lustel, Madrid, págs.144-147 y 167-177 y toda la bibliografía que allí se cita. 


\section{Fundaciones del sector público}

Junto con las sociedades mercantiles públicas existen las fundaciones del sector público, bajo la categoría de "organismos de naturaleza privada de titularidad pública". Se trata de las fundaciones constituidas con una aportación mayoritaria, directa o indirecta, de la Administración de la Comunidad Autónoma o sus entes instrumentales, y también aquellas otras cuyo patrimonio fundacional, con carácter permanente, esté integrado en más de un 50 \% por bienes o derechos cedidos por entidades del sector público autonómico (art. 55 LSP).

La creación, la modificación de la escritura de constitución y la extinción de fundaciones del sector público requiere, como en el caso de las sociedades públicas, acuerdo previo del Consejo de Gobierno. También requieren acuerdo las cesiones o aportaciones de bienes y derechos a una fundación previamente constituida cuando, como consecuencia de éstas, se produzca la circunstancia que se convierta en una fundación de iniciativa pública mayoritaria, como también los actos o los negocios que determinen la pérdida del carácter de fundación del sector público autonómico (art. 56 LSP). Los estatutos de las fundaciones del sector público se tienen que elevar al Consejo de Gobierno, junto con la propuesta de acuerdo por el cual se dispone la creación (art. 57 LSP).

Ejerce el protectorado de las fundaciones del sector público la Administración de la Comunidad Autónoma mediante las consejerías de adscripción correspondientes, de acuerdo con el que se establezca reglamentariamente (art. 55.3 LSP). En virtud del Decreto 61/2007, de 18 de mayo, de regulación del Registro Único de Fundaciones de la Comunidad Autónoma de las Islas Baleares y de organización del ejercicio del protectorado, la inscripción de las entidades de naturaleza fundacional en el Registro Único de Fundaciones es requisito necesario porque adquieran personalidad jurídica y sólo procede cuando, previamente, las fundaciones y sus estatutos hayan sido reconocidos y calificados siguiendo las pautas establecidas en el Decreto 61/2007 mencionado.

Con carácter general, el régimen jurídico general a las fundaciones del sector público es el mismo que se aplica a las sociedades mercantiles públicas, antes mencionado (art. 55.2, 49 y 50 LSP).

\section{Consorcios}

La Administración de la Comunidad puede constituir consorcios con otras administraciones públicas para el cumplimiento de finalidades de interés común (art. 84 LRJACA). Concretamente, según indica el artículo 85 de esta Ley, el Gobierno de las Islas Baleares puede crear consorcios -así como acordar la integración de la Administración de la Comunidad Autónoma a consorcios- con otras administraciones públicas y, si es el caso, con entidades sin ánimo de lucro. En el primer supuesto, el acuerdo de creación tiene que incluir los estatutos del consorcio, mientras que en el segundo, el acuerdo de integración tiene que incluir la ratificación o la adhesión en unos estatutos preexistentes. Finalmente, el apartado 4 del artículo 85 de la LRJACA determina que sólo aquellos consorcios que estén financiados mayoritariamente por la Administración de la Comunidad Autónoma, o aquellos a los que corresponda la designación de más de la mitad de los miembros de los órganos de dirección, se sujetarán en cuanto a su organización y actividad al ordenamiento autonómico, y, por lo tanto, serán considerados como administración instrumental stricto sensu.

La principal novedad de la LSP del sector público es que acoge la regulación de los consorcios como entes de naturaleza corporativa junto con las otras tipologías de entes instrumentales de naturaleza institucional de la Comunidad Autónoma. La LSP delimita conceptualmente los consorcios, quedando éstos integrados en el sector público de la Comunidad Autónoma y sujetos al ordenamiento autonómico (art. 58 y 59.2 LSP), de acuerdo con los criterios de vinculación que establece el artículo 85.4 de la LRJACA. Se trata de ente de naturaleza pública que se rigen, a todos los efectos y sin perjuicio de las particularidades que se establezcan en sus estatutos, por el Derecho administrativo; les es aplicable el régimen jurídico propio de los organismos públicos y, en particular, de los organismos autónomos (art. 58.2 LSP), con la excepción del régimen de control interno de la Intervención General de la Comunidad Autónoma; en este ámbito se mantiene el control financiero -posterior- propio del sector público empresarial y fundacional. La creación de los consorcios requiere el acuerdo previo del Consejo de Gobierno, mientras que la fusión de consorcios requiere, además, el acuerdo de los órganos de dirección correspondientes de cada uno de los consorcios afectados (art. 59 LSP). En todo caso, la creación o la adhesión a un consorcio requiere que se formalice el convenio de colaboración correspondiente con los otros entes consorciados, en el cual se tiene que fijar el régimen de financiación y el número de representantes de cada ente a los órganos de dirección (art. 58 LSP).

Para acabar, no se puede concluir este apartado sin antes destacar el avance que para efectiva racionalización administrativa -impuesta por Europa mediante la Directiva 2006/123/CE del Parlamento Europeo y del Consejo, de 12 de diciembre de 2006, relativa a los servicios en el mercado interior- ha supuesto la entrada en vigor de la Ley del sector público instrumental de las Islas Baleares. En cumplimiento del mandato contenido en la Disposición 
transitoria primera de la LSP, mediante el Decreto 93/2011, de 2 de septiembre, se ha creado la Comisión de Análisis y Propuesta de Reestructuración del Sector Público Instrumental, cuya labor ha culminado, en el momento de redactar estas líneas, en la aprobación de un Acuerdo del Consejo de Gobierno, de 30 de marzo de 2012, por el que se aprueba la primera fase del Proyecto de Reestructuración, y que se ha realizado sobre diversos ámbitos funcionales (salud, investigación y ciencia, agricultura, desarrollo empresarial y nuevas tecnologías, servicios sociales, investigación sanitaria, deporte y turismo), en virtud de lo dispuesto en la Disposición adicional octava de la Ley 9/2011, de 23 de diciembre, de 23 de diciembre, de presupuestos generales de la Comunidad Autónoma de las Islas Baleares para el año $2012^{21}$.

\section{ALGUNOS ASPECTOS DE LA ACTUACIÓN ADMINISTRATIVA}

\section{La competencia de la Comunidad Autónoma sobre régimen jurídico y procedimiento administrativo}

Con la asunción por parte de la Comunidad Autónoma de la competencia exclusiva en materia de "organización, régimen y funcionamiento de sus instituciones de autogobierno" (art. 10.1 EAIB 1983), la Comunidad empieza configura el componente administrativo del Gobierno, dando así cumplimiento al artículo 41 del Estatuto de 1983, que mandaba crear la "estructuración de una administración pública propia", de la que ya se ha dado cuenta. Además, la Comunidad tenía que llevar a cabo el desarrollo legislativo y la ejecución del "régimen jurídico y de responsabilidad de la Administración de la Comunidad Autónoma” (art. 11.1 EAIB 1983), en el marco de la legislación básica del Estado y de acuerdo con las disposiciones contenidas en el apartado 1.18 del artículo 149 de la Constitución. En virtud de los artículos 30.1 y 31.1 del Estatuto de autonomía vigente de 2007 -que básicamente reproducen los artículos 10.1 y 11.1 del Estatuto de 1983, antes mencionados-, desde su origen la competencia de la Comunidad Autónoma para establecer la organización administrativa propia, así como el régimen jurídico de su actuación, ha estado limitada por la competencia exclusiva del Estado para regular "las bases del régimen jurídico de las administraciones públicas" y "el procedimiento administrativo común, sin perjuicio de las especialidades derivadas de la organización propia de las comunidades autónomas", el sentido que prevé el artículo 149.1.18 de la Constitución. Entre los títulos competenciales sobre "régimen jurídico" y "procedimiento administrativo común" a los que se refiere el artículo 149.1.18 de la CE, ha existido siempre una gran interrelación que a menudo ha provocado alguna confusión. La doctrina del Tribunal Constitucional ha configurado una noción muy extensa de la materia régimen jurídico, que ha provocado que a veces haya habido alguna dificultad para distinguir manera clara la diferencia que podía haber entre ambos títulos competenciales ${ }^{22}$. En síntesis, la materia régimen jurídico estatal tiene que limitarse a la producción y eficacia de los actos administrativos y a las cuestiones básicas de la organización de la Administración; y la materia procedimiento administrativo común debe contener los principios informadores de la vía reglada de producción de la voluntad administrativa -de aplicación general a todas las administraciones públicas-, así como las garantías mínimas de los ciudadanos en relación a la actividad administrativa. El legislador estatal ha seguido esta doctrina en la LRJPAC, que constituye el marco de referencia obligada por las comunidades autónomas, la cuales, por un lado, ejercen sus competencias de desarrollo respetando las bases del régimen jurídico estatales, y por otra, regulan las especialidades procedimentales inherentes al ejercicio de sus competencias sustantivas.

La LRJPAC además de recoger principios constitucionales básicos de las Administraciones públicas, como el principio de legalidad de la actuación administrativa, de objetividad y de imparcialidad (arts. 9.3 y 103), desarrolla el contenido del artículo 105.C) de la Constitución ("La ley regulará:... c) el procedimiento a través del cual deben producirse los actos administrativos, garantizando, cuando proceda, la audiencia del interesado"). Hay que destacar como norma fundamental del régimen administrativo el artículo 57.1 de la LRJPAC, que concreta el principio de legalidad de los actos administrativos manifestando su presunción de validez. A partir de esta premisa, la adecuación de los actos administrativos al ordenamiento jurídico puede ser destruida a posteriori por los afectados mediante la interposición de los correspondientes recursos administrativos o contenciosos administrativos. De esta presunción de validez se deriva que el propio artículo 57.1 de la LRJPAC determine también que los actos administrativos producirán efectos desde el momento en que se dicten, salvo que en ellos se disponga otra cosa. Así

21 Entre otras medidas, cabe destacar la integración de las tres fundaciones hospitalarias existentes en el Servicio de Salud de las Islas Baleares (Fundaciones Hospital Son Llàtzer, Hospital de Manacor y Hospital Comarcal de Inca), la fusión de dos empresas públicas del sector agrícola (SEMILLA e IBABSA), la extinción de dos sociedades relacionadas con el desarrollo tecnológico (ParcBit y BITEL) y su posterior integración en otra entidad de ese sector (IBIT) o la extinción de 20 consorcios.

22 Por procedimiento administrativo común, la STC 227/1988 ha afirmado que se tenía que entender "la determinación de los principios o normas que definen la estructura general del curso procedimental [...], la forma de elaboración, los requisitos de validez y de eficacia, las formas de revisión y los medios de ejecución de los actos administrativos, incluyendo las garantías generales de los particulares en el seno del procedimiento". En el marco de estas reglas comunes, que tienen que ser respetadas por las comunidades autónomas, éstas tienen entonces la competencia para regular los procedimientos inherentes al ejercicio de sus competencias sustantivas. Tras un periodo titubeante (STC 15/1989), el Tribunal Constitucional ha confirmado finalmente esta postura doctrinal en la STC $17 / 1990$. 
pues, la Ley mencionada prevé una producción inmediata de efectos del acto, previsión que tiene su fundamento en su presunción de legalidad. Por ello, la Ley también permite que la Administración pueda ejecutar de forma forzosa sus actos, de acuerdo con los artículos 56, 94 y 95 de la LRJPAC.

En el ámbito de las Islas Baleares, la LRJACA tiene como referente de obligado cumplimiento la LRJPAC, tal como se desprende en su artículo 1 ("Esta ley regula, en el marco del régimen jurídico común a todas las administraciones públicas, la organización y el funcionamiento de la Administración de la Comunidad Autónoma de las Islas Baleares, como también las especialidades del procedimiento que le son aplicables"). En el marco de los principios fundamentales de la ley estatal, la LRJACA recoge en su Título V (arts. 42-69) algunos aspectos específicos del régimen jurídico la actuación administrativa, como el uso de la lengua catalana, la información administrativa, la duración de los procedimientos y los efectos del silencio administrativo, la formación de los expedientes administrativos, la revisión de los actos en vía administrativa, las reclamaciones previas, la actuación en materia tributaria, la contratación administrativa, la potestad sancionadora y los procedimientos sobre responsabilidad patrimonial.

\section{La transparencia y la simplificación en la actuación administrativa}

Otros aspectos jurídicos de la actuación administrativa, relacionados con la transparencia y simplificación, son también regulados por la LRJACA en 2003, aunque de manera tímida. No es hasta la aprobación del Estatuto de Autonomía de 2007 que la normativa se desarrolla en este ámbito. A partir de ese momento, se intensifican notablemente las regulaciones que afectan a la calidad y a la gobernanza en la actuación administrativa, en clara sintonía con la normativa comunitaria, básicamente la Carta de Derechos Fundamentales de la Unión Europea, de 7 de diciembre de 2000, y la Directiva 2006/123/CE del Parlamento Europeo y del Consejo, de 12 de diciembre de 2006, relativa a los servicios en el mercado interior; así como también con la normativa básica estatal, LRJPAC, LOFAGE y, especialmente, la Ley 11/2007, de 22 de junio, de acceso electrónico de los ciudadanos a los servicios públicos. Se inicia una nueva etapa en la Administración autonómica en la que empieza a desplegarse todo un conjunto de principios, herramientas, estrategias e instrumentos que dirigen su actuación administrativa, destinadas al establecimiento de más calidad en su organización y en la prestación de sus servicios.

En el ámbito europeo, el Tratado de Lisboa de 13 de diciembre de 2007 reconoce los derechos, las libertades y los principios enunciados en la Carta de los Derechos Fundamentales, antes citada, y proclama que dicha Carta tiene el mismo valor jurídico que los tratados. El artículo 41 de la Carta establece el derecho a una buena administración, definido como el que toda persona tiene respecto del hecho de que las instituciones, los órganos y los organismos de la Unión traten sus asuntos de manera imparcial y equitativa y en un plazo razonable. El artículo 42 reconoce el derecho de todo ciudadano de la Unión y de toda persona física o jurídica que resida en un estado miembro, o tenga el domicilio social, al acceso a los documentos de las instituciones, órganos y organismos de la Unión, sea cual sea su soporte.

La Directiva relativa a los servicios en el mercado interior, arriba referida, persigue de manera específica la simplificación y la reducción de cargas administrativas, y su transposición al derecho español se realiza mediante la Ley 17/2009, de 23 de noviembre, sobre el libre acceso a las actividades de servicios y a su ejercicio, y la Ley 25/2009, de 22 de diciembre, de modificación de diversas leyes para su adaptación a la Ley 17/2009, de 23 de noviembre. En el ámbito de la Administración General del Estado, y como legislación básica, la LRJPAC, en la redacción del artículo 3 recogió en 1992 una serie de principios que hoy todavía tienen mucha fuerza (eficacia, cooperación, eficiencia y servicio a la ciudadanía y de transparencia y de participación); principios que posteriormente en 1997 fueron revisados por el artículo 3 de la LOFAGE, esta vez con más atención a las demandas de la ciudadanía, en dos bloques: uno de organización (incluyendo los de simplicidad, claridad y proximidad a la ciudadanía y coordinación) y otro de funcionamiento (eficacia en el cumplimiento de los objetivos fijados, eficiencia en la asignación y utilización de los recursos públicos, programación y desarrollo de objetivos y control de la gestión y de los resultados, responsabilidad en la gestión pública, racionalización y agilidad de los procedimientos administrativos y de las actividades materiales de gestión, servicio efectivo a la ciudadanía, objetividad y transparencia de las actuaciones administrativas y cooperación y coordinación con el resto de administraciones públicas). Importa destacar también la Ley estatal 11/2007, de 22 de junio, de acceso electrónico, antes citada, cuyo artículo 4 recoge los principios generales relacionados con las tecnologías de la información, entre los cuales cabe destacar el principio de simplificación administrativa destinado a reducir de manera sustancial los tiempos y plazos de los procedimientos administrativos, y el principio de transparencia y publicidad del procedimiento, de cara a obtener la máxima difusión, publicidad y transparencia de las actuaciones administrativas ${ }^{23}$.

23 El Real Decreto 951/2005, de 29 de julio, que establece el marco general para la calidad en la Administración general del Estado, es un hito destacable en este recorrido, ya que tiene por objeto definir el espacio común para la mejora de la calidad. La creación de la Agencia de Evaluación de Políticas y Calidad de Servicios del Gobierno de España, de 1 de desembre de 2006, es una referencia inexcusable en este ámbito. 
En las Islas Baleares, el artículo 14, apartado 1, del EAIB 2007 instaura el derecho a una buena administración y al acceso a los archivos y registros administrativos de las instituciones y administraciones públicas de las Islas Baleares; y el apartado 2 se refiere al derecho de la ciudadanía a disfrutar de servicios públicos de calidad (especialmente en los ámbitos de la justicia, la educación y la salud, según se deduce a lo largo del Estatuto de autonomía) y que las administraciones públicas traten sus asuntos de forma objetiva e imparcial y en un plazo razonable, en la senda marcada por la Carta europea de los Derechos Fundamentales de 2000 y, en el ámbito autonómico, por el artículo 36 de la LRJACA.

El artículo 34 de la LRJACA establece como principio general de la actuación administrativa autonómica velar por la mejora continua de los servicios y de las prestaciones públicas mediante modelos de gestión orientados a la innovación y a la evaluación de los resultados por los usuarios. Especialmente relevante es el artículo 39 de la Ley mencionada, que recoge el derecho a la calidad de los servicios públicos y, en concreto, a exigir los niveles de calidad establecidos en la prestación de los servicios. Además, dispone que el Gobierno tiene la obligación de adoptar alguno de los modelos reconocidos y existentes en relación con la evaluación de la calidad de los servicios públicos, con el fin de que los órganos de la Administración puedan autoevaluar, periódicamente, su actividad. En un ámbito más concreto, el apartado 3 del artículo 39 prevé la posibilidad de que el Gobierno establezca premios u otro tipo de incentivos para promover entre sus órganos la mejora continua de la calidad de los servicios. Cabe destacar también la referencia en artículo 40 de la LRJACA al derecho de petición y a la posibilidad de expresar sugerencias o quejas relativas al funcionamiento de los servicios públicos.

Pese a las reservas normativas autonómicas que acabamos de ver, lo cierto es que no es hasta la primera década del siglo XXI cuando empieza regularse algún aspecto relacionado con la necesidad de aumentar los niveles de exigencia de calidad en la Administración autonómica. Destaca el Acuerdo del Consejo de Gobierno de 5 de diciembre de 2007, de aprobación del Plan Estratégico de Calidad del Gobierno de las Islas Baleares, el Acuerdo del Consejo de Gobierno de 8 de mayo de 2009, para impulsar la simplificación y la reducción de cargas administrativas en la Administración de la Comunidad Autónoma de las Islas Baleares, y el Acuerdo del Consejo de Gobierno de 18 de diciembre de 2009, por el cual se aprueba la implementación del sistema de gestión por procesos de la Comunidad Autónoma.

Con posterioridad, mediante la Ley 12/2010, de 12 de noviembre, para su adaptación a la Directiva 2006/123/ CE relativa a los servicios en el mercado interior, se modifican varios aspectos de la LRJACA que merecen destacarse. Primero, se introduce en la referida Ley, mediante la modificación de su artículo 45, la regulación general de la declaración responsable y de comunicación previa (concepto y procedimiento aplicable); en segundo lugar, se establece el derecho de información de los modelos de declaración responsable y comunicación previa -que habrán de incluir de manera expresa y clara los requisitos exigidos en cada caso (todo ello deberá publicarse en la web de la Comunidad Autónoma)-, así como la necesidad de tener permanentemente actualizada la relación de todos los procedimientos en que se admitan dichos modelos [apartado d), art. 41.2]; y, en tercer lugar, se prevé el derecho de efectuar por vía telemática los trámites necesarios para acceder a una actividad de servicios y a su ejercicio (apartado 3, art. 37).

En 2011, tras la aprobación del Acuerdo del Consejo de Gobierno de 18 de marzo, relativo al fomento de la transparencia en la Administración de la Comunidad Autónoma de las Islas Baleares, se aprueba la Ley 4/2011, de 31 de marzo, de la buena administración y del buen gobierno. El artículo 4 reconoce el derecho a la información administrativa y las vías de acceso a esta información a través de medios electrónicos, con respecto a los principios de igualdad y universalidad. El artículo 7 garantiza el cumplimiento de la mencionada Ley estatal 11/2007, de acceso electrónico, de forma que este derecho se constituye como un deber para la Administración autonómica. Así mismo, se prevé el despliegue reglamentario de la sede (dirección) electrónica, la creación de registros electrónicos, la promoción de la generalización del expediente electrónico como alternativa al expediente en papel y el sistema de archivo electrónico de documentos. Los artículos 13 a 17 regulan aspectos de la simplificación administrativa, entre los que cabe resaltar la obligación de confeccionar el inventario de los procedimientos administrativos de competencia de la Administración y sus entes, como también el deber de mantenerlos constantemente actualizados y publicarlos en la página web institucional. Se reconoce expresamente el derecho de los administrados de no aportar documentación que ya esté en poder de la Administración y establece el deber de las entidades públicas de garantizar ese derecho de manera real y efectiva. Por lo que se refiere a la transparencia en la gestión (arts. 18 a 22), se regulan específicamente cuatro supuestos en los que ese principio tiene una aplicación especial: contratación pública, gestión de servicios públicos, convenios de colaboración y régimen de ayudas y subvenciones. Finalmente, también se regula el sistema de quejas y sugerencias, mediante el sistema de implantación de Cartas Ciudadanas (arts. 25 y 26), y se crean varias modalidades de premios a la calidad y las buenas prácticas (arts. 27,28 y 29). Además de regular la buena administración, la Ley 4/2011, de 31 de marzo, se refiere también al buen gobierno. 
La apuesta por una buena administración y por unos servicios públicos de calidad requiere la potenciación y la consolidación de la calidad democrática en aquello que tiene que ver con el ejercicio de la acción de gobierno de las instituciones públicas y la manera de actuar de los líderes políticos. En el ámbito estatal, se empiezan a adoptar iniciativas encaminadas a ejemplificar la gobernanza, que van desde el impulso a códigos éticos basados en la austeridad y la honestidad, la transparencia y la responsabilidad en la rendición de cuentas, pasando por la evaluación de los resultados de las intervenciones públicas ${ }^{24}$. En relación al buen gobierno, la citada Ley balear 4/2011 se centra en tres aspectos, básicamente: i) el gobierno en funciones, ii) la mejora de la regulación y la calidad normativa y iii) la transparencia política.

Así, en primer lugar, la Ley 4/2011 establece algunas obligaciones que vinculan a los gobiernos en funciones para evitar actuaciones que puedan condicionar o dificultar el acceso a la información o el funcionamiento del gobierno entrante (art. 32). En segundo lugar, la Ley 4/2011 revaloriza los principios informadores de la política legislativa de calidad normativa y de mejora de la regulación, mediante la exigencia de evaluación previa de las normas y su impacto en la sociedad (art. 42). En tercer lugar, por lo que se refiere a la transparencia y el control de los cargos públicos, la Ley 4/2011 impone unos deberes de información al Parlamento para los nombramientos de altos cargos y la información sobre retribuciones y declaraciones de estos últimos (arts. 37, 38, 39). También crea la denominada Oficina de Evaluación Pública de las Islas Baleares, en la que se incorpora el Registro de Intereses y Actividades y el Registro de Patrimonio -creados con anterioridad por la Ley 2/1996, de 19 de noviembre, de incompatibilidades de los miembros del gobierno y altos cargos de la Comunidad Autónoma-. La Oficina tiene por objeto la función de coordinar y desarrollar las acciones de evaluación en la Administración autonómica, y también de ejercer, entre otras, la gestión del registro de las evaluaciones que se lleven a cabo, de desarrollo de un observatorio de la gestión pública y de seguimiento y evaluación del cumplimiento de las medidas de transparencia e integridad (art. 50).

\section{BIBLIOGRAFÍA}

Blasco Esteve, A. (1994): "La Administración institucional de la Comunidad Autónoma de las Islas Baleares", en VV.AA., Administración Instrumental (Libro homenaje a Manuel Francisco Clavero Arévalo), Tomo II, Civitas/Instituto García Oviedo (Universidad de Sevilla), Madrid.

Cabotà Sainz, P. (2008): “Artículo 31.1. "Régimen jurídico y sistema de responsabilidad de la Administración de la Comunidad Autónoma”", A. Blasco Esteve (dir.), Comentarios al Estatuto de Autonomía de las Islas Baleares, Thomson-Civitas, págs. 498-502.

Calafell Ferrà, V. (2008): "Artículo 39. Las instituciones", A. Blasco Esteve (dir.), Comentarios al Estatuto de Autonomía de las Islas Baleares, Thomson-Civitas, págs. 645-653.

Colom Pastor, B. (2001): Veinticinco años de autonomía balear, Marcial Pons, Govern de les Illes Balears, Universitat de les Illes Balears.

- (2004): Les claus polítiques del procés autonòmic balear, Institut d'Estudis Autonòmics, Govern de les Illes Balears, Palma.

Gómez-Ferrer Morant, R. (1999): "Incidencia de la Constitución sobre el Derecho administrativo", Revista de Administración Pública, 150, págs. 159-208.

Montoya Martín, E. (2012): "Reflexiones sobre el sector público instrumental en un contexto de crisis económica: la inaplazable hora de la racionalización" (mimeo), en VII Congreso Asociación Española de Profesores de Derecho Administrativo, Tarragona.

Mora Martí, B. (2008): “Disposición transitoria primera. Comisión Mixta de Transferencies”, A. Blasco Esteve (dir.), Comentarios al Estatuto de Autonomía de las Islas Baleares, Thomson-Civitas, págs. 1465-1476.

Santamaría Pastor, J. A. (1988): Fundamentos de Derecho Administrativo I, Centro de Estudios Ramón Areces, Madrid.

- (2009): Principios de Derecho Administrativo General I, $2^{\mathrm{a}}$ ed., lustel, Madrid.

Segura Ginard, LL. (2004): “Notes sobre organització a la nova llei de règim jurídic de l’Administració balear”, Revista jurídica de les Illes Balears, 2, págs. 167-179.

- (2008a): “Artículo 79. La administración propia”, A. Blasco Esteve (dir.), Comentarios al Estatuto de Auto-

24 Véase el Código del Buen Gobierno de los miembros del Gobierno y de los altos cargos de la Administración General del Estado, aprobado por la Orden APU/516/2005, de 3 de marzo, y la Ley 5/2006, de 10 de abril, de regulación de los conflictos de intereses de los Miembros del Gobierno y de los Altos Cargos de la Administración General del Estado, así como su despliegue normativo, mediante el Real decreto 432/2009, de 27 de marzo. 
nomía de las Islas Baleares, Thomson-Civitas, págs. 1011-1015.

- (2008b): “Artículo 80. Ejecución de las funciones administrativas”, A. Blasco Esteve (dir.), Comentarios al Estatuto de Autonomía de las Islas Baleares, Thomson-Civitas, págs. 1016-1024.

Socias Camacho, J. M. (2006): Fundaciones del sector público. En especial el ámbito sanitario, lustel, Madrid.

- (2008): "Disposición adicional tercera. Entidades y organismos para prestar servicios (I. Administración instrumental autonómica)", A. Blasco Esteve (dir.), Comentarios al Estatuto de Autonomía de las Islas Baleares, Thomson-Civitas, págs. 1425-1435.

Socias Camacho, J. M., Trías Prats, B. (2008): Administració institucional. Consideracions generals i règim del ens de la Comunitat Autònoma de les Illes Balears, Tirant lo Blanch, Valencia. 
